\title{
Reproductive Cycle and Fecundity Tristramella simonies (Gunther, 1864) (Teleostei: Cichlidae) in the Northern Great River (Lattakia, Syria)
}

\author{
aFadia Dib, bAdib A. Saad*, cAbdellatif Ali \\ a Tishreen University, Faculty of Agriculture, Marine Sciences Laboratory and Aquatic Environment, P.O Box 1408, \\ Lattakia, Syria. \\ ${ }^{b}$ Tishreen University, Faculty of Agriculture, Department of Basic Sciences, Laboratory of Marine Sciences and Aquatic \\ Environment, P.O Box 1408, Lattakia, Syria. \\ ${ }^{c}$ General commission for Fisheries, Jable, Syria.
}

\section{A R T I C L E I N F O}

\section{Article History}

Received: May 24, 2020

Revised: July 27, 2020

Accepted: October 18, 2020

\section{Keywords}

Tristramella simonis

Cichlidae

Northern Great River

Fecundity

Reproduction

\section{A B S T R A C T}

This research was conducted to study the reproductive cycle and fecundity of the fish Tristramella simonis in the Northern Great River (Nahr Alkabeer Alshmali) north of Lattakia city. 263 individuals were collected from the northern great river, during the period between July 2017 and June 2018. Samples were collected every 15 days using gill nets, which its pores diameter ranged from 16 to $20 \mathrm{~mm}$ and using cages $(1 \times 1 \times$ $1 \mathrm{~m})$. The total length of the collected fish ranged from 9.5 to $16.5 \mathrm{~cm}$, and their weights ranged from 19.5 to $112.27 \mathrm{~g}$. Samples contained (128 females) and (88 males) and (47) undetected. Results of Gonado Somatic Index (GSI) showed that the reproduction period was between April and August with three obvious peaks of maturity. Where the highest value of GSI was $(10.06 \pm 8.46) \%$ for females and $(0.13 \pm 0.05) \%$ for males. Results of Hepato Somatic Index (HSI) was concurrence highly with the ecological and physiological changes, which result from changes in sexual activity during the reproductive cycle. Where the highest value of HSI attained $3.79 \pm 1.86 \%$ for females and attained $3.95 \pm 1.38 \%$ for males. In the first sexual maturity, the length attained $13.31 \mathrm{~cm}$ for females and $(14.87 \mathrm{~cm})$ for males. The sexual rate was $(1: 0.7)$, which means $40.7 \%$ males and $59.3 \%$ females in the population. The absolute fecundity ranged from 940 to 1229 egg. While the relative fecundity ranged between 158- 215 egg/ g of ovary weight. Egg diameter during reproduction season ranged between 2.4$4 \mathrm{~mm}$, with several sizes, which mean a relatively long reproduction term.

*Corresponding Author: Adib Saad

Email: adibsaad52@gmail.com

(C) The Author(s) 2020.

\section{INTRODUCTION}

The aquatic environment in Syria is exposed to many hazards, due to human activities on the freshwater runways (dam building, manufactories, Sewer systems etc.) (Ali et al., 2013). In addition to iniquitous and irregular catch of fish (as a catch in reproduction season or using small pores of gill nets), and illegal catch (using toxins and explosives) (El-Karachily et al, 2001). These led to the lack of natural stored fish in Syrian water and a fast decadence of the aquatic environment. Then led to distributing unwanted fish species in some aquatic Syrian environments, which compete with the economic species, in addition to causing settlement a new species, that was not existing previously in the Syrian water (Ali et al., 2015).

As the biology of one species differs from geographic region to another, knowing the nature and behavior of each fish species, its bio-characters and act with the 
surroundings is important. Therefore, the present study was conducted to study biology and reproduction and feeding of the species Tristramella simonies (Günther, 1864), which was newly recorded in the Northern Great River (Nahr Alkabeer Alshmalee) (Borkenhagen and Freyhof, 2009). The effect of its removal on the local and foreign species, and on the farms of carp Cyprinus carpio in these river runways was also tested. This study aims to:

- Determine the reproduction periods of Tristramella simonies in the Nahr Alkabeer Al Shmalee

- Determine the fish length at the first sexual maturity, and

- $\quad$ Evaluate the fecundity of Tristramella simonis.

\section{MATERIALS AND METHODS}

\section{Study Area}

The Nahr Al Kabeer Al Shamalee is considered one of the longest rivers in Lattakia. Its length attained about $96 \mathrm{~km}$. The total area of its basin is $1097 \mathrm{~km}^{2}$. Most of the basin is surrounding by mountain area, covered in general with pines forests. The farming is spread intensively in the fluvial valleys and the direct versants. The fluvial net is intensive in the flow, but it dries in Summer, especially after building 16 Tishreen dam on the river at $12 \mathrm{~km}$ northeast of Lattakia (Figure1) (MOWR, 2010).

The river locates on the northeast side of Lattakia. It flows at Louaa AL Eskandaroun on 1600 m latitude. Many small runways feed it, such as Almour Spring, Ein Aldelb, Ein Alsallour, Ein Alashraa, The Black River, Koufaria River, and many other small feeders (GORS, 2017).

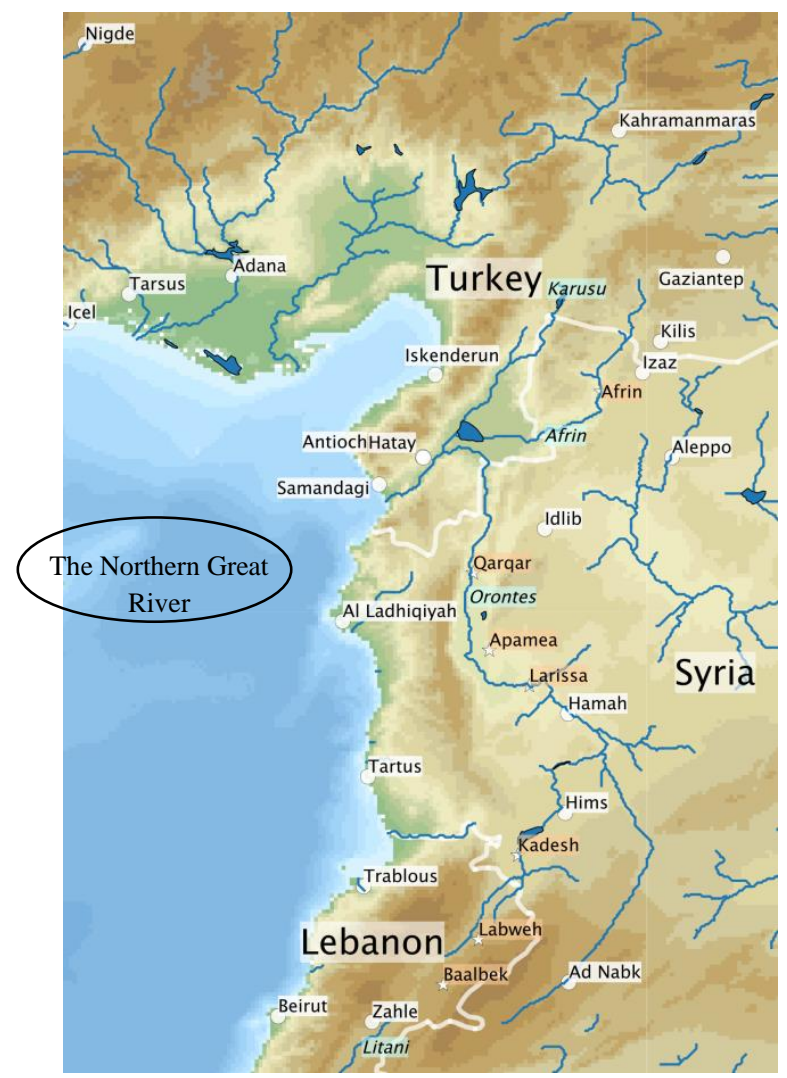

Figure 1. Study Area: Nahr al- Kabeer Alshmali (https:images.app.goo.gl).

\section{Fish Samples Collect}

Fieldwork: Fish samples were collected every 15 days,

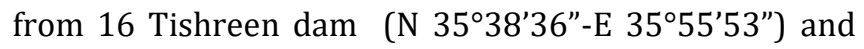
river water (figure 2), using gill nets having pores diameters ranged between $16-20 \mathrm{~mm}$, and length ranged between $10-300 \mathrm{~m}$, with $2-5 \mathrm{~m}$ height. The cages $(1 \times 1 \times 1$ m) had $25 \mathrm{~mm}^{2}$ pores. The cages and nets were put in the river in the afternoon and fishes were collected in the morning, next day. This process was done between July 2017 until June 2018.

After collecting, fish was put in formaldehyde (9\%), and brought to the laboratory. The samples attained (263 
individuals) had total length ranged from 9.5 to $16.5 \mathrm{~cm}$ (just one male attained $18 \mathrm{~cm}$ as a long). The weight ranged between 19.5 and $112.27 \mathrm{~g}$. Individuals contained
128 females and 88 males and 47 undetected individuals because these individuals did not attain sexual maturity.

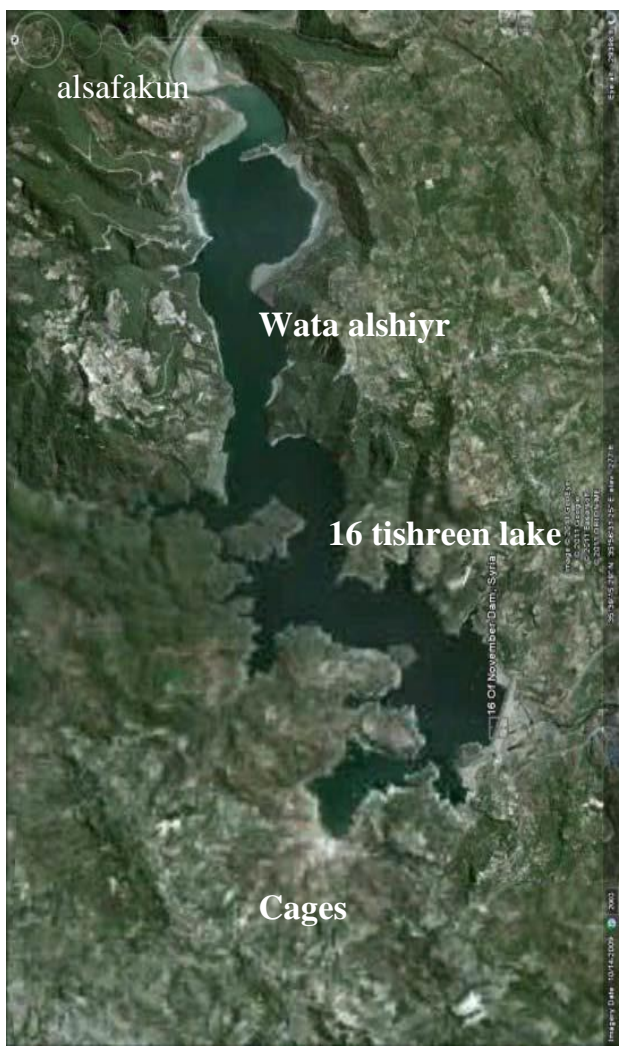

Figure 2. Locations of samples (google earth).

Laboratory work: Fish samples were moved directly to the Laboratory of Marine Sciences, Tishreen University at Lattakia, Syria and were classified morphologically (Beckman, 1962; Coad, 2010). Morph metric measurements were taken as total length (T.L) and Standard Length (S.L) (Pravdin, 1966). These fishes were then dissected, gonads were insulated and weighted, and then fixated by formaldehyde (5\%) to calculate Gonado Somatic Index (GSI) percentage using the following equation (Bougis, 1952): \%GSI= Gw*100/Ew

Where GSI: Gonado Somatic Index. GW: Gonads Weight (g), EW: Eviscerated Weight (g).

Then the liver was insulated and weighted (hithermost $0.01 \mathrm{~g}$ ) to calculate HIS \% (Hepato Somatic Index) using the following equation (Pravdin, 1966): \%HSI = LW*100/ Ew

Where HIS: Hepato Somatic Index, LW: Liver Weight (g), EW: Eviscerated Weight (g).
The length in the first sexual maturity was determined when $1+50 \%$ of a group attained a specific length, it was the sexual maturity degree (Gunderson, 1977; Love, 1970).

To study the fecundity and egg diameters, the wet weight method was followed. 11 adult females were taken. Eggs were washed, put on filtered paper to absorb the extra water. $0.1 \mathrm{~g}$ of gonad eggs were weighted. This process was repeated several times to different regions of the ovary (the upper- meso and lower part). Results were treated to get eggs number in $1 \mathrm{~g}$ of ovary weight (Sabour, 1995; Saad et al, 2006) (figure 3).

The absolute and relarive fecundity was calculated using the formulas given by Bagenal (1978).

The Absolute fecundity: The absolute fecundity was calculated as:

$$
\mathrm{Fa}=\mathrm{Gw} \times \mathrm{D}
$$

Where Fa: the absolute fecundity, GW: gonads weight (g), D: Eggs number/ $1 \mathrm{~g}$ of ovary weight. 
Relative Fecundity: Similarly, relative fecundity was calculated as (Bagenal, 1973):

$$
\mathrm{Fr}=\mathrm{Fa} / \mathrm{Sw}
$$

Where Fr: relative fecundity, Fa: absolute fecundity, SW:

The total weight or ovary weight (g).
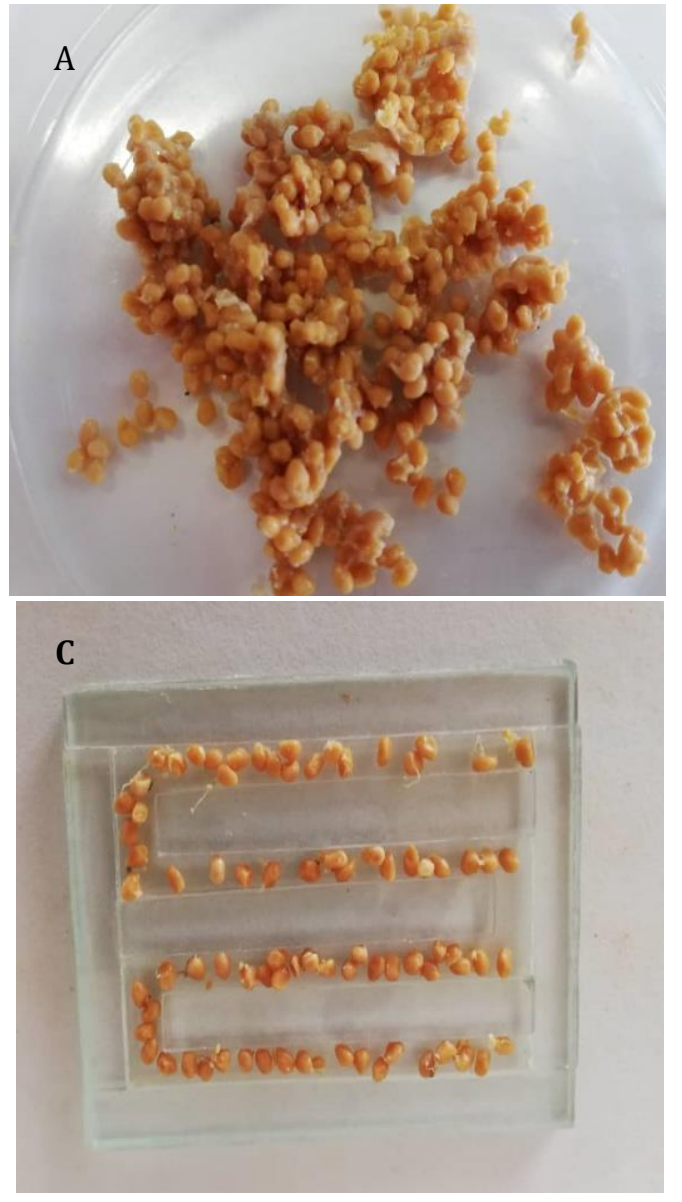

\section{Statistical Study}

The statistical study was done using SPSS-V 18 to analysis the results and drawing the graphic lines.
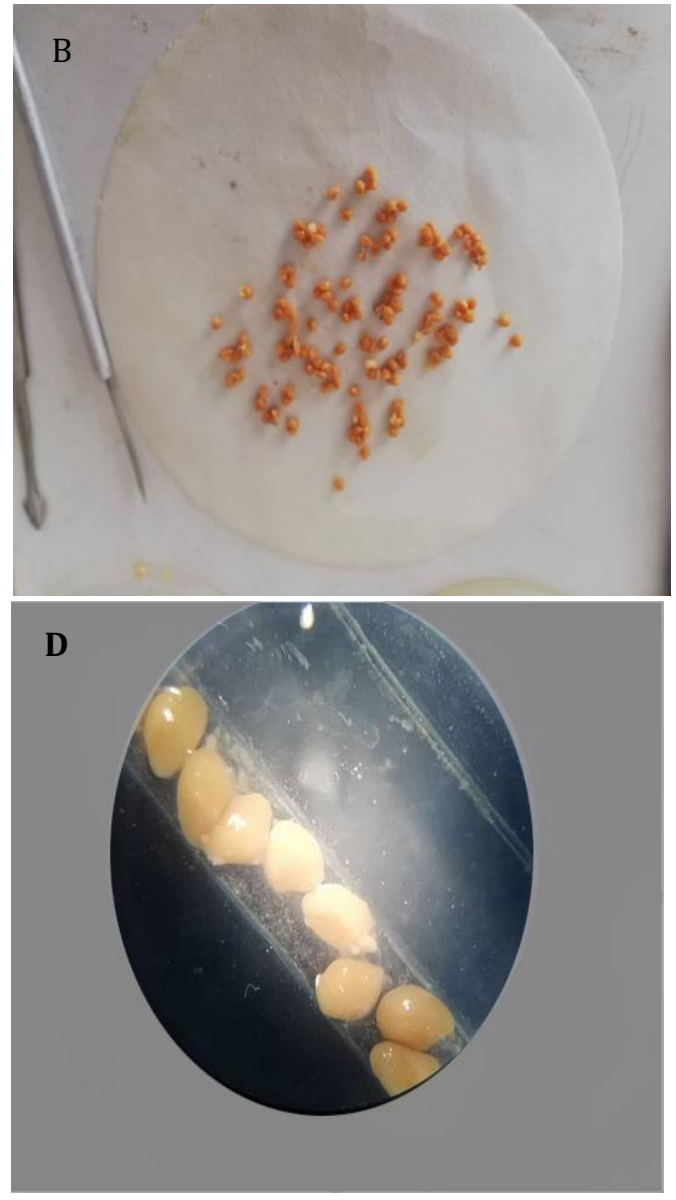

Figure 3. Fecundity study and egg numbering: A: eggs adding into Petri dishes, B. eggs putting on filtered paper to absorption the water, C: counting chamber, D: counting the eggs under a microscope.

\section{RESULTS AND DISCUSSION:}

\section{Morphological characters}

The morphological study was performed depending on body shape. The fish head was medium in size while the lower jaw was longer than the upper one. Teeth were located on the two jaws in 3-4 rows. 3-4 rows of scales were located on the chap. A black spot was also located on the gills covering. The pectoral fins almost reached the anus fins origin.

The color of fishes was olive brown on the dorsal and sidling sides while the abdomen was lighter. About 8 dark lines were located on the body side in younger individuals (Kullander, 1998). The mean body length attained $9.8 \mathrm{~cm}$ as minimum while $25 \mathrm{~cm}$ as maximum (Snoeks, Teugels, 1991) (figure 4).

\section{Monthly changes of GSI \% (Gonado Somatic Index)}

For females: Results showed that GSI began increasing during March and the maximum value observed was 2.46 $\pm 2.41 \%$. The curve in figure 5 shows the number of peaks, where it was notably increasing during April and reached a maximum of $8.46 \pm 10.06 \%$. Then it showed a reduction during May and reached $3.65 \pm 4.48 \%$. The return showed an increase during June, where its value reached $5.40 \pm 4.54 \%$. In addition to this, the third peak was observed during August which was $1.99 \pm 1.97 \%$. The index after that showed another reduction to attain 
the least value of it after the reproduction period in September with the value of $0.08 \pm 0.33 \%$. The last reduction may be returned to lay eggs from the mature ovary.

For males: Results showed that GSI for males began increasing during March with the value of $0.04 \pm 0.05 \%$. The curve showed different peaks. The GSI value increased during April, where it reached $0.050 .013 \%$ and decreased during May (0.08 $\pm 0.011 \%)$. The return increase was observed during June with a value of 0.03 $\pm 0.012 \%$. In addition to this, the third peak can be seen during August where it reached $0.05 \pm 0.08 \%$. It attained the least value after the reproduction period during November and reached $0.02 \pm 0.05 \%$ (figure 6). The reason for this reduction is due to voidance of sperm by mature castrate.
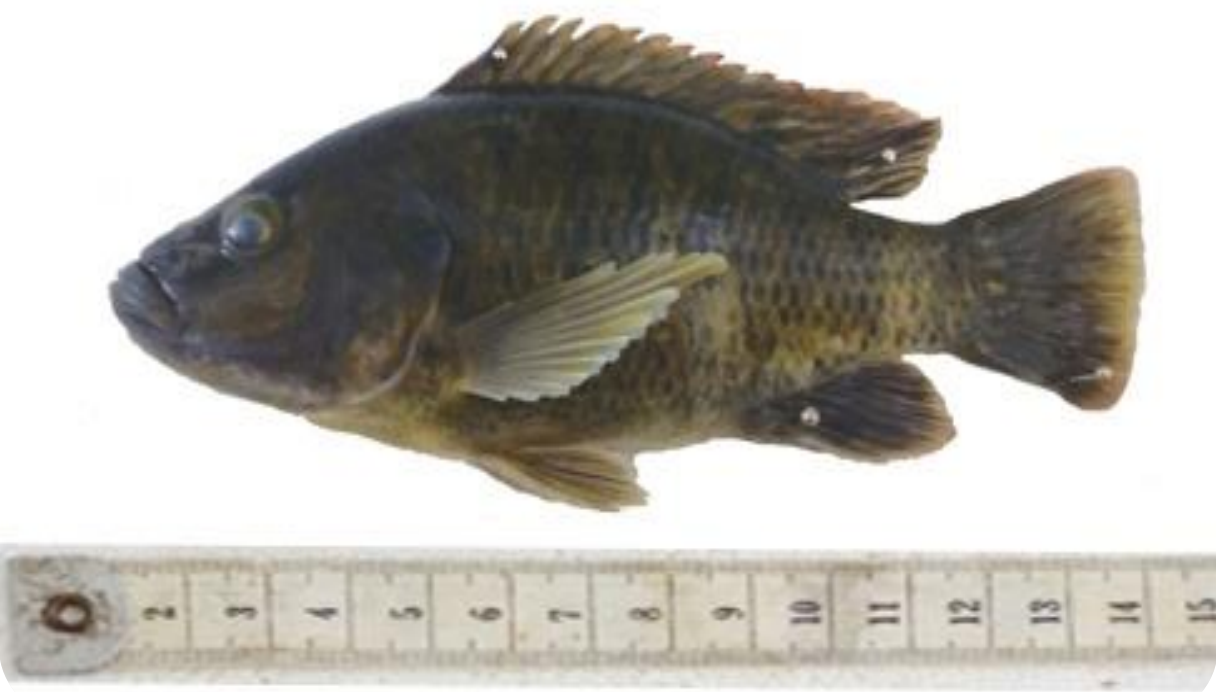

Figure 4. General form of the species Tristramella simonies (13 $\mathrm{cm}$ as long, 55.26g as weight).

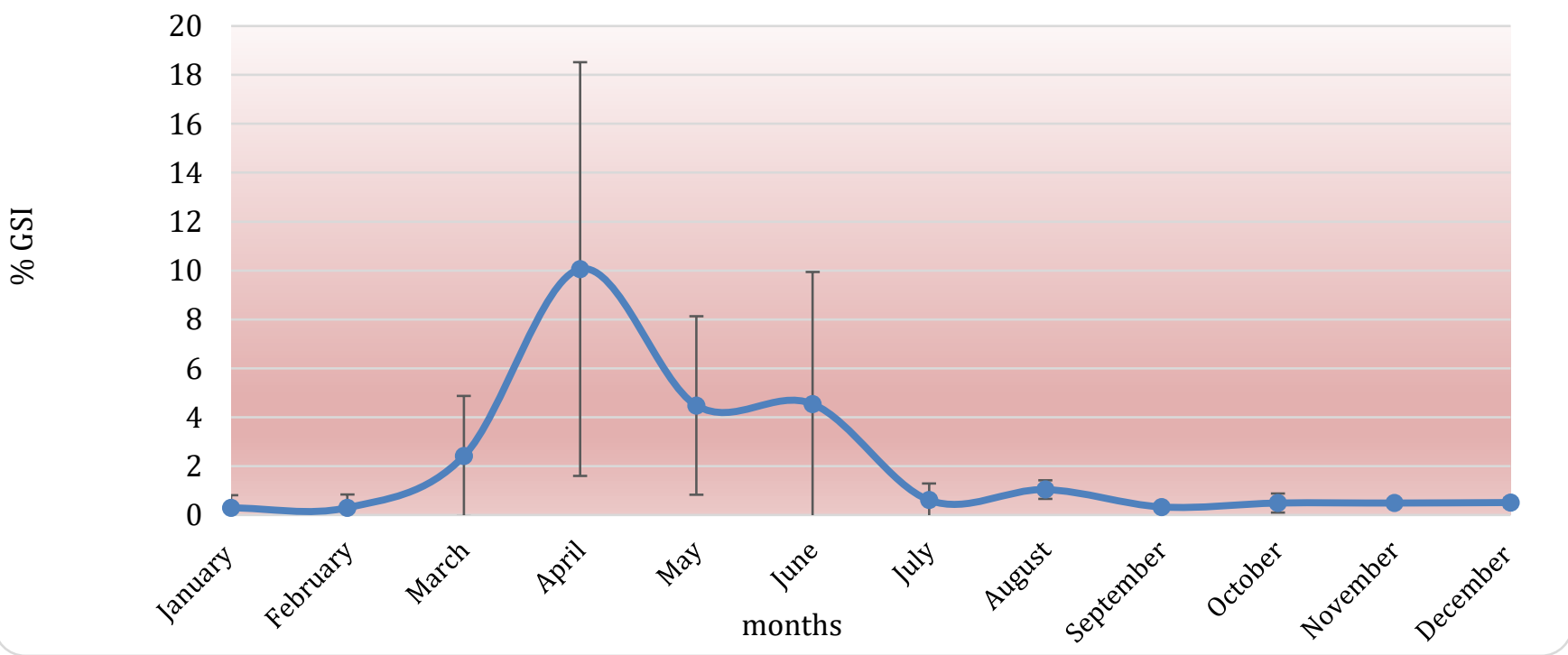

Figure 5. Changes of GSI \% value to the females of the species T. simonis. 


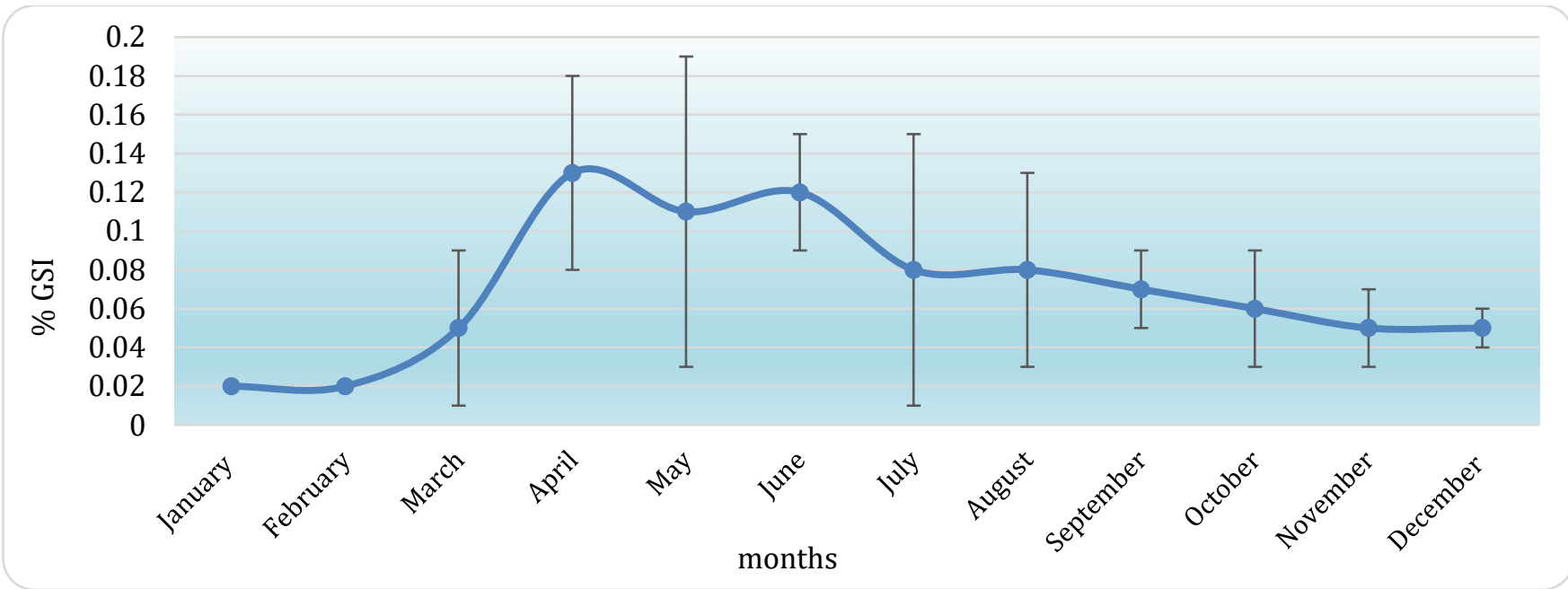

Figure 6. Changes of GSI \% value to the males of the species T. simonis.

\section{Monthly changes in HSI \% (Hepato Somatic Index)}

Females: Results show that the highest value of HSI in the females was $1.86 \pm 3.79 \%$ during reproduction months. That means females of this species did not depend on the liver reserves to consume energy which is necessary to gonads growth, but it depends on the nutrient from the surrounding and stored the extra as energy in the liver. This causes an increase in HSI values. The least value observed was $0.77 \pm 1.41 \%$ during December. This low value fit winter and the bad nutrient conditions, so fish go to use all available energy to do their biological processes (figure 7).

Males: Results show the highest value of HSI was observed during March $1.38 \pm 3.95 \%$. This period is directly prior to the reproduction period. When it compared with the curve of GSI \%, it was notable that the peak followed directly by a peak in gonads growth. This could be explained due to the males get the energy to gonads growth from liver reserves (figure 7).

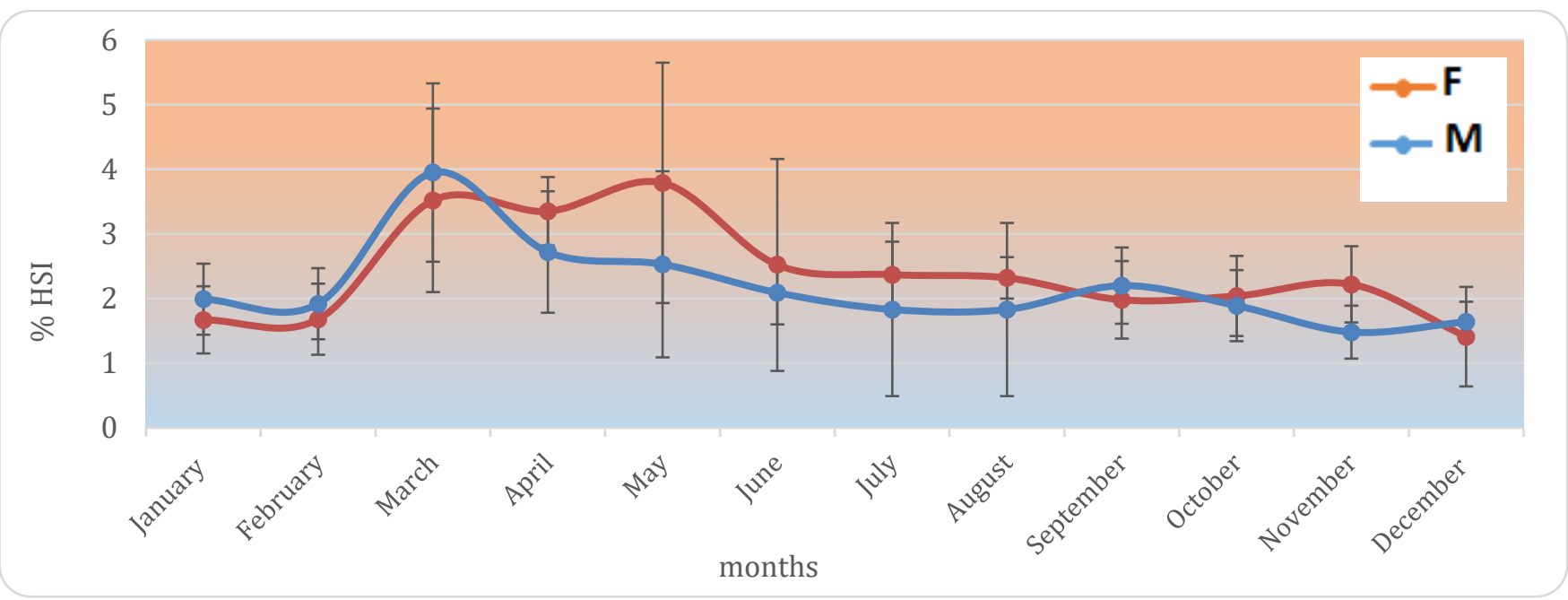

Figure 7. Monthly changes of HSI \% to each of females and males of the species T. simonis (F= Female, M= Male).

\section{Length at the first sexual maturity}

All fishes having a length of less than $10 \mathrm{~cm}$ were immature in both females and males. With an increase in length, the number of mature individuals increased to become more than $50 \%$ at the length of $13.31 \mathrm{~cm}$ (females) and $14.87 \mathrm{~cm}$ (males) as shown in table 1 and figure 9.

Differences in the length at the first sexual maturity may be attributed to fish origin from different regions, genetic factors and ecological conditions. Temperature changes may be one of the factors behind the varying density of the fish population. 
Table 1. Changes in sexual maturity rates according to length groups in the species Tristramella simonis.

\begin{tabular}{|c|c|c|c|c|c|c|c|c|c|}
\hline \multicolumn{5}{|c|}{ Males } & \multicolumn{5}{|c|}{ females } \\
\hline $\begin{array}{c}\text { mean of } \\
\text { length } \pm \text { SD }\end{array}$ & $\mathrm{n}$ & immature $\%$ & mature $\%$ & length group $(\mathrm{cm})$ & $\begin{array}{c}\text { mean of } \\
\text { length } \pm S D\end{array}$ & $\mathrm{n}$ & immature \% & mature $\%$ & length group $(\mathrm{cm})$ \\
\hline 0 & 5 & 100 & 0.0 & $10.1-11$ & 11 & 7 & 85.71 & 14.29 & $10.1-11$ \\
\hline $12 \pm 0$ & 10 & 80 & 20.0 & $11.1-12$ & $22.73 \pm 0.12$ & 18 & 83.33 & 16.67 & $11.1-12$ \\
\hline $12.78 \pm 0.45$ & 9 & 55.6 & 44.4 & $12.1-13$ & $12.57 \pm 0.13$ & 26 & 50 & 50 & $12.1-13$ \\
\hline $13.89 \pm 0.18$ & 16 & 50 & 50.0 & $13.1-14$ & $13.31 \pm 0.29$ & 32 & 46.87 & 53.13 & $13.1-14$ \\
\hline $14.87 \pm 0.25$ & 24 & 45.8 & 54.2 & $14.1-15$ & $14.55 \pm 0.63$ & 23 & 34.78 & 65.22 & $14.1-15$ \\
\hline $16.26 \pm 0.52$ & 22 & 40 & 60.0 & $>15$ & $16.24 \pm 0.29$ & 22 & 22.73 & 77.27 & $>15$ \\
\hline
\end{tabular}

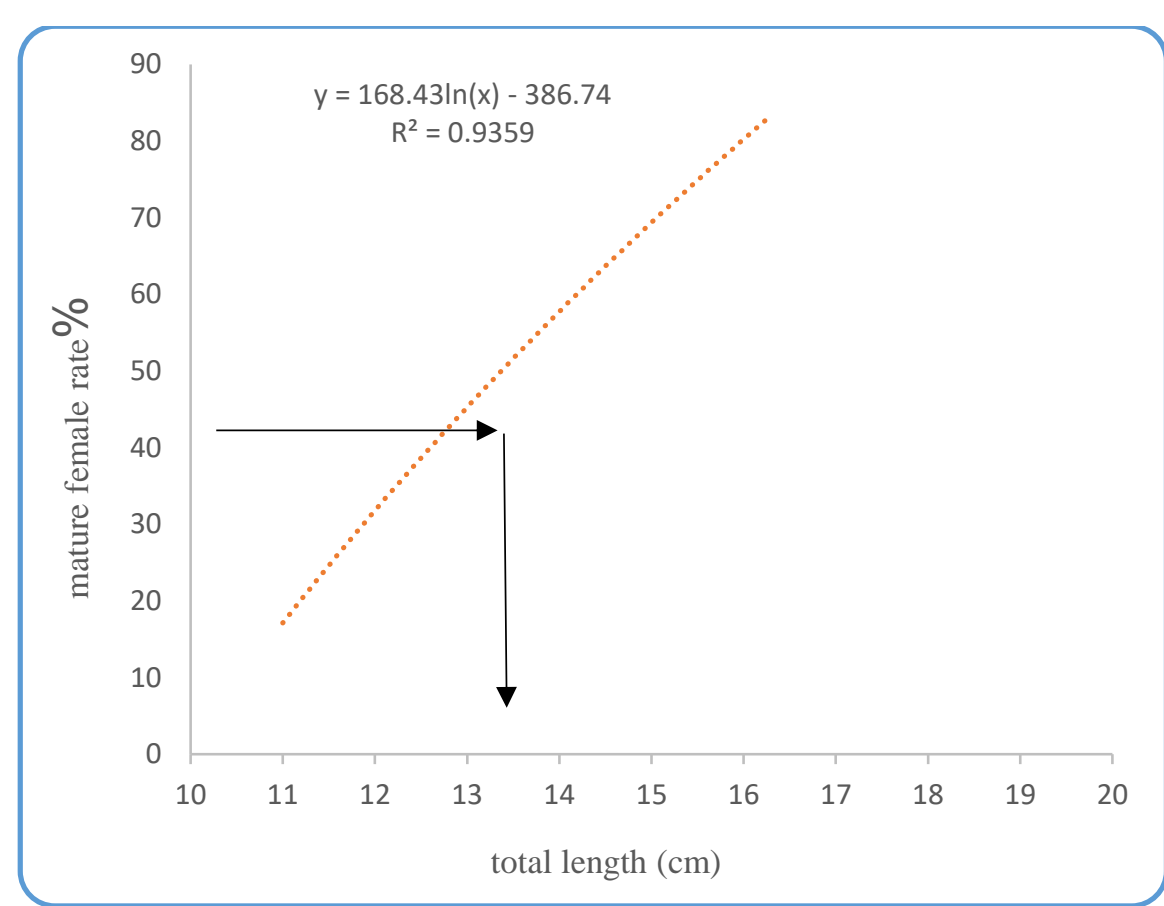

Figure 8. the length in the first sexual maturity in the females of the species Tristramella simonis during reproduction season.

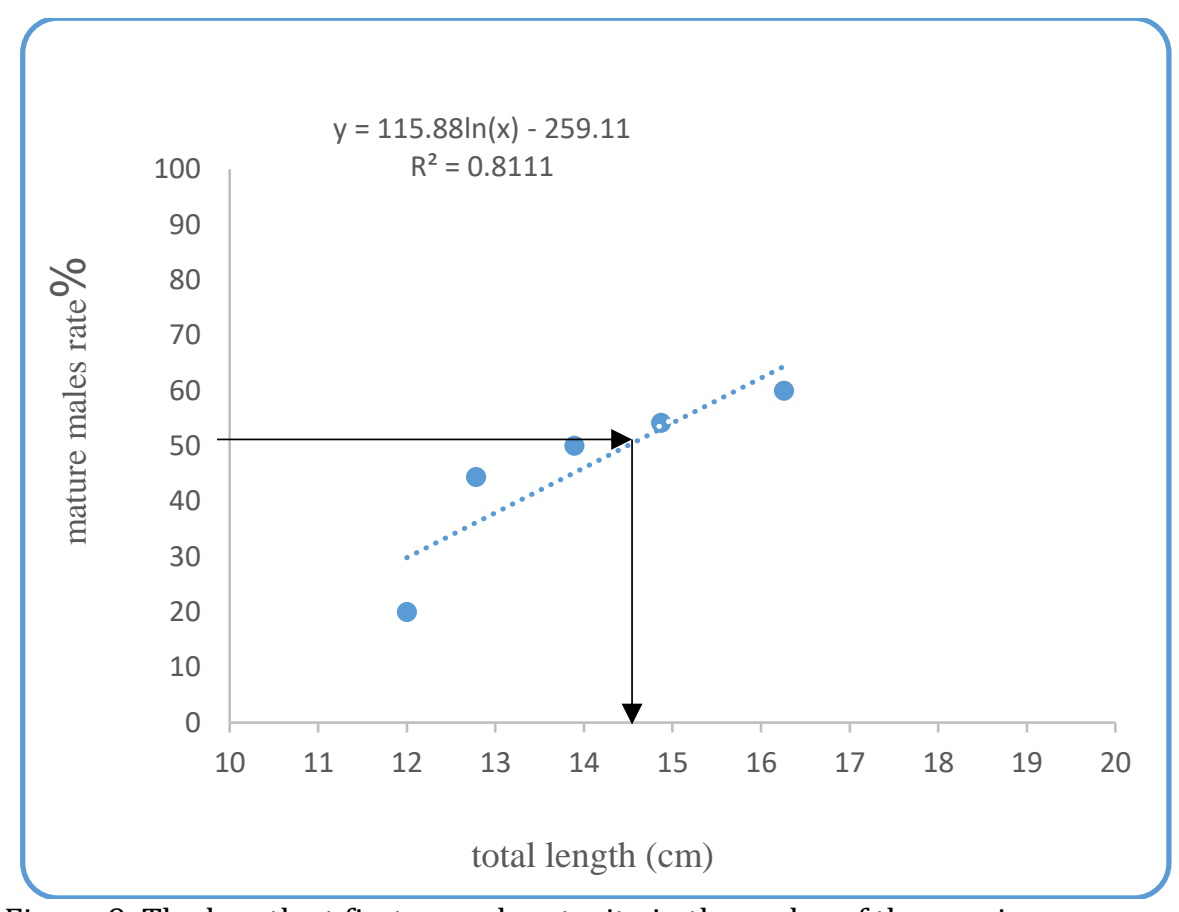

Figure 9. The length at first sexual maturity in the males of the species Tristramella simonis during reproduction season. 


\section{Fecundity}

Absolute fecundity: Values of absolute fecundity in females was estimated by counting eggs that ranged between 940 1229 egg with their length ranged between $13-16.5 \mathrm{~cm}$, and weights ranged between $45.28-98.42 \mathrm{~g}$. It attained the highest value 1229 egg at the length of $14 \mathrm{~cm}$ and the weight of $61.11 \mathrm{~g}$ (table 2). It was a clear trend for increased absolute fecundity as the ovarian weight increased and the relationship appeared positive and strong $(\mathrm{Fa}=104.544 \mathrm{Gw}$
+421) $\left(\mathrm{R}^{2}=0.97\right)$ (Figure 10). As for the relationship between the total female weight and absolute fecundity, it was a very weak linear inverse relationship, and by observing the value of the coefficient of determination $(\mathrm{R}=$ 0.031), it can be said that the total weight of the individual has no significant effect on the value of absolute fecundity (Figure 11). Study of the correlation between absolute fecundity and total body length was performed and was found to be an inverse weak relation (figure 12).

Table 2. The absolute and relative fecundity of females of the species Tristramella simonis.

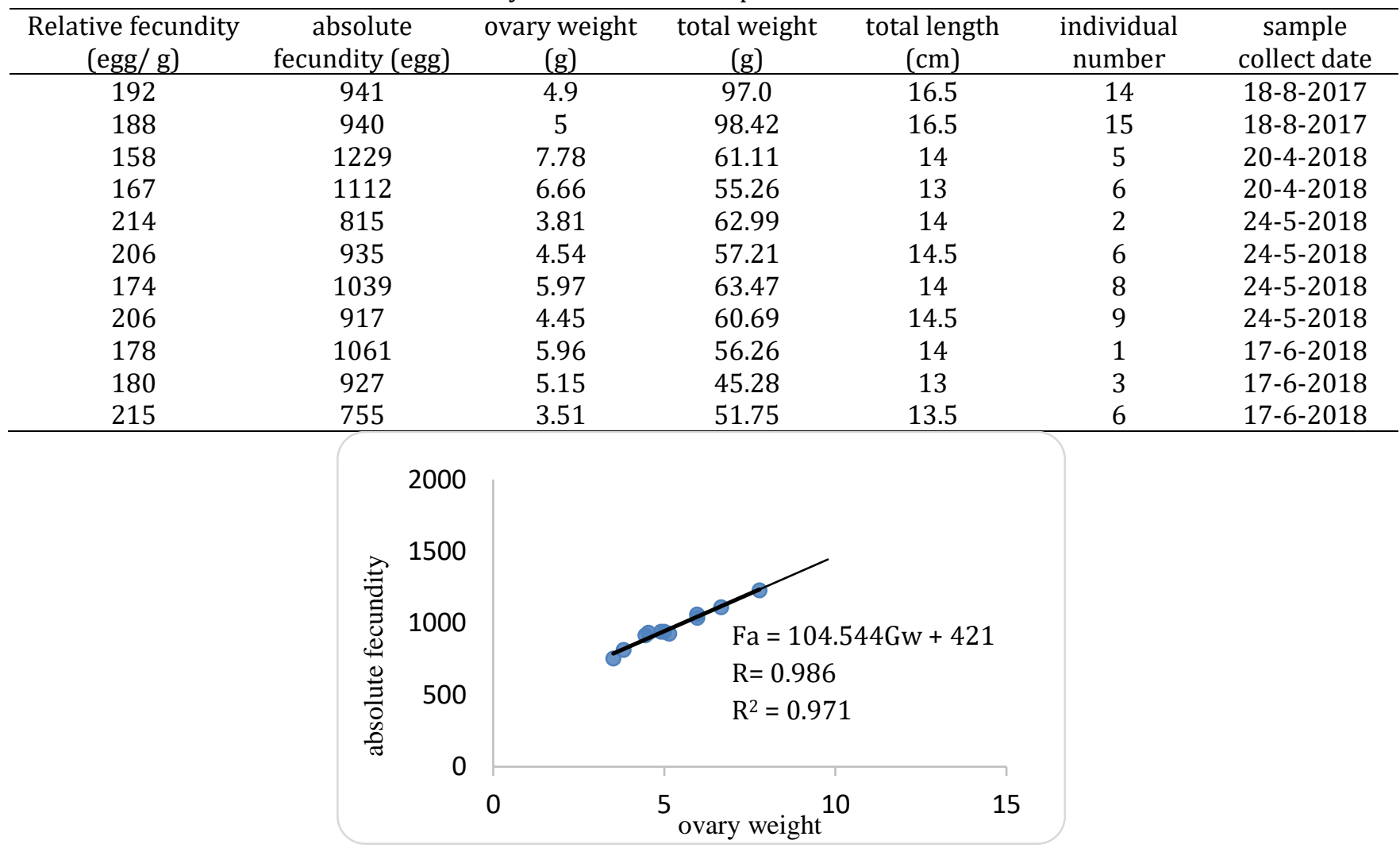

Figure 10. The relation between the absolute fecundity and the ovary weight in females of the species Tristramella simonis.

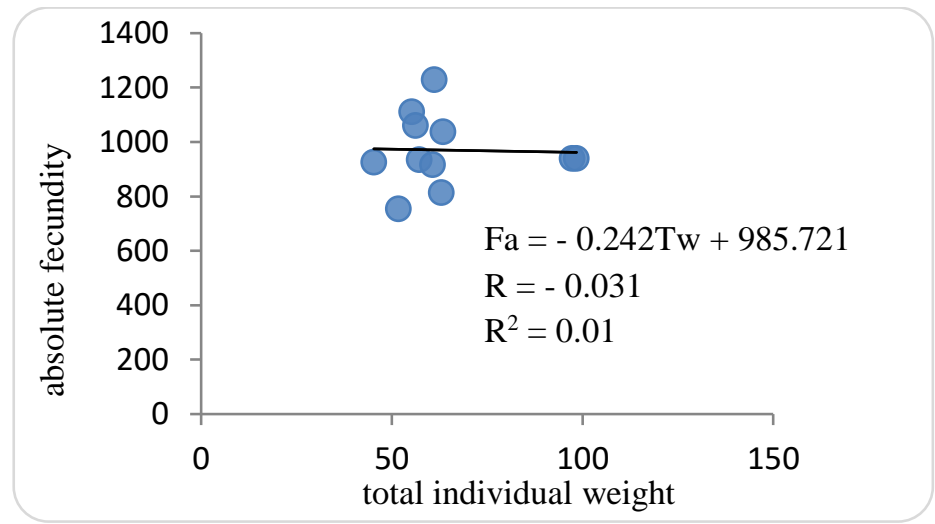

Figure 11. The relation between the absolute fecundity and the total weight in females of the species Tristramella simonis. 


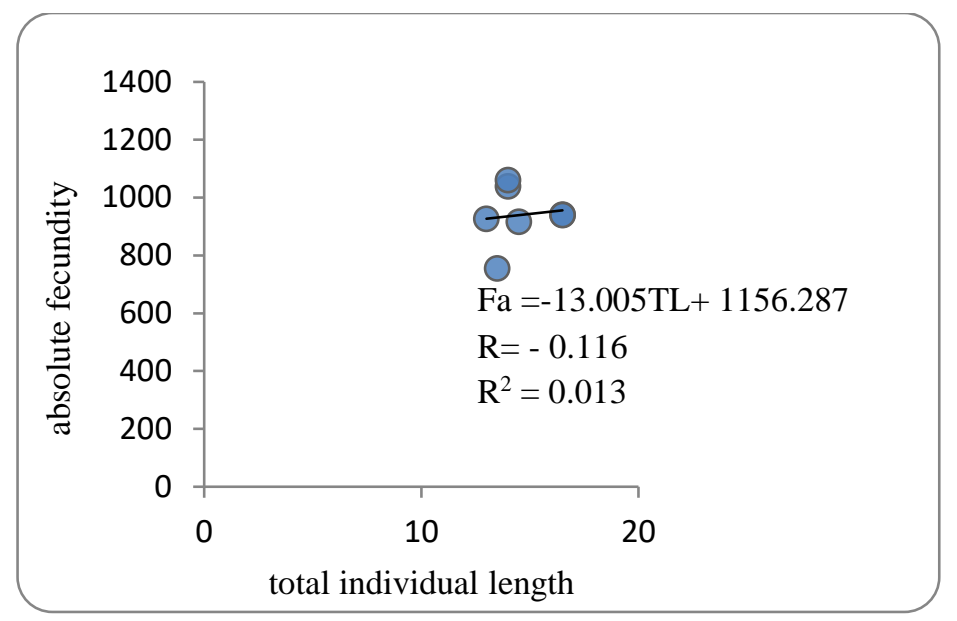

Figure 12. The relation between the absolute fecundity and the total length in females of the species Tristramella simonis.

Relative Fecundity: Results showed that the relative fecundity of the species $T$. simonis females whose length ranged between 13- $16.5 \mathrm{~cm}$, and weight ranged between 45.28- $98.42 \mathrm{~g}$ had relative fecundity of 158- $215 \mathrm{egg} / 1 \mathrm{~g}$ of ovary weight. It attained the highest value of 215 egg at a length of $13.5 \mathrm{~cm}$ and a weight of $51.75 \mathrm{~g}$ (Table 2).

\section{Development of egg diameters}

Egg diameters of 10 adult females ranged between (2.4 $4 \mathrm{~mm}$ ) during reproduction season, in the females having length ranged between $13-16.5 \mathrm{~cm}$. At the sexual maturity peak, the diameters ranged between 3-3.3 mm. The highest diameter of the egg during the reproduction season was $4 \mathrm{~mm}$, but the rate of egg like this was very low that attained about $4 \%$ of the total mature egg.
Results showed that the existing of several sizes of egg in the studied samples, a relatively long reproduction season in the studied species was observed (Figure $13 \mathrm{a}$-c).

Also, the number of times the eggs are laid at the Tilapia fish is an adaptation to the exploitation of food, and it is also part of the requirements of the reproduction strategies for these fish to secure a number of eggs to meet the changes in environmental conditions and provide the environment with a new number of larvae to ensure the continuity of the species (Khalifa, 2017).

Results also showed three peaks in the curve of egg diameters, which means three reproduction periods in the year (figure 14).

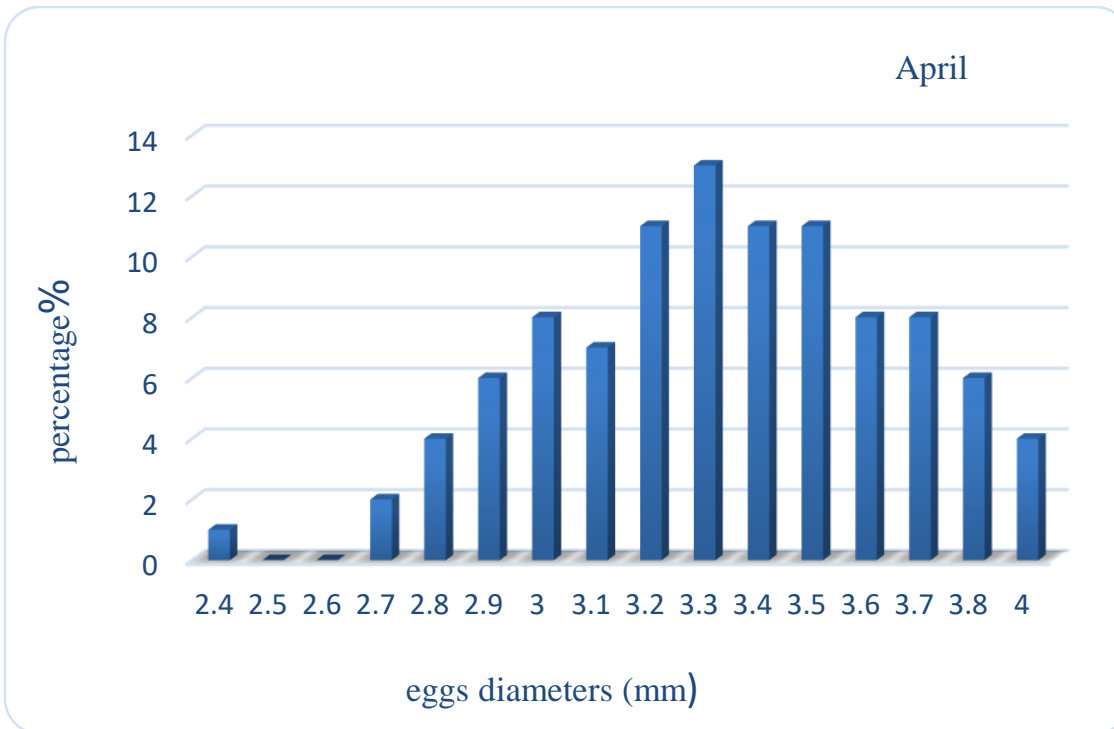

Figure 13 (a). Development of egg diameters and their percentages of females of the species Tristramella simonis during reproduction season (April). 


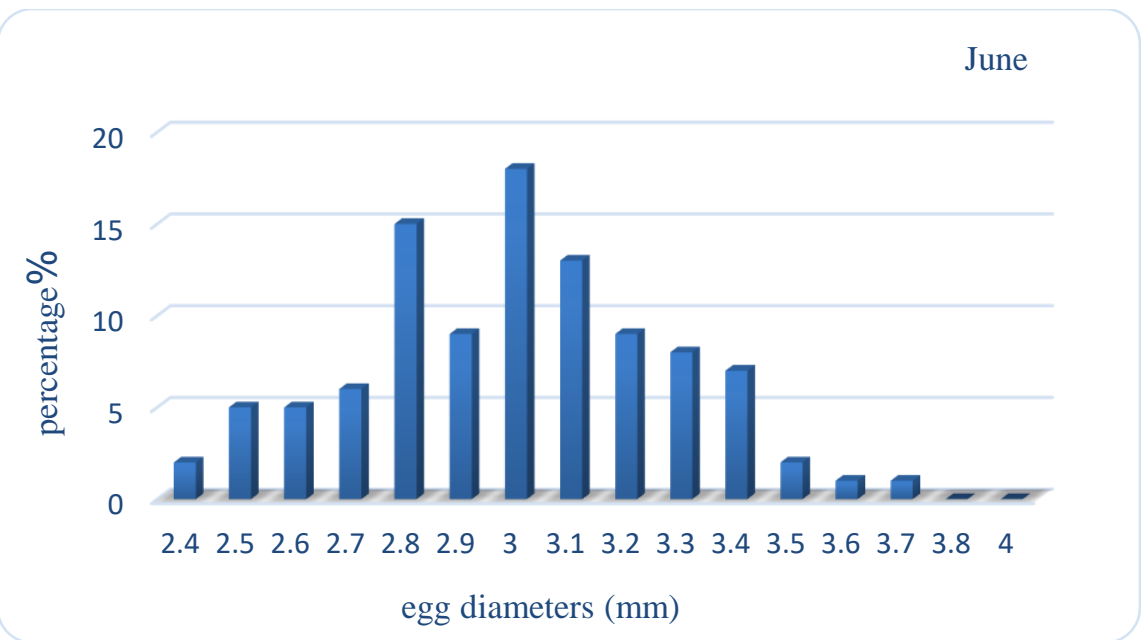

Figure 13 (b). Development of egg diameters and their percentages of females of the species Tristramella simonis during reproduction season (June).

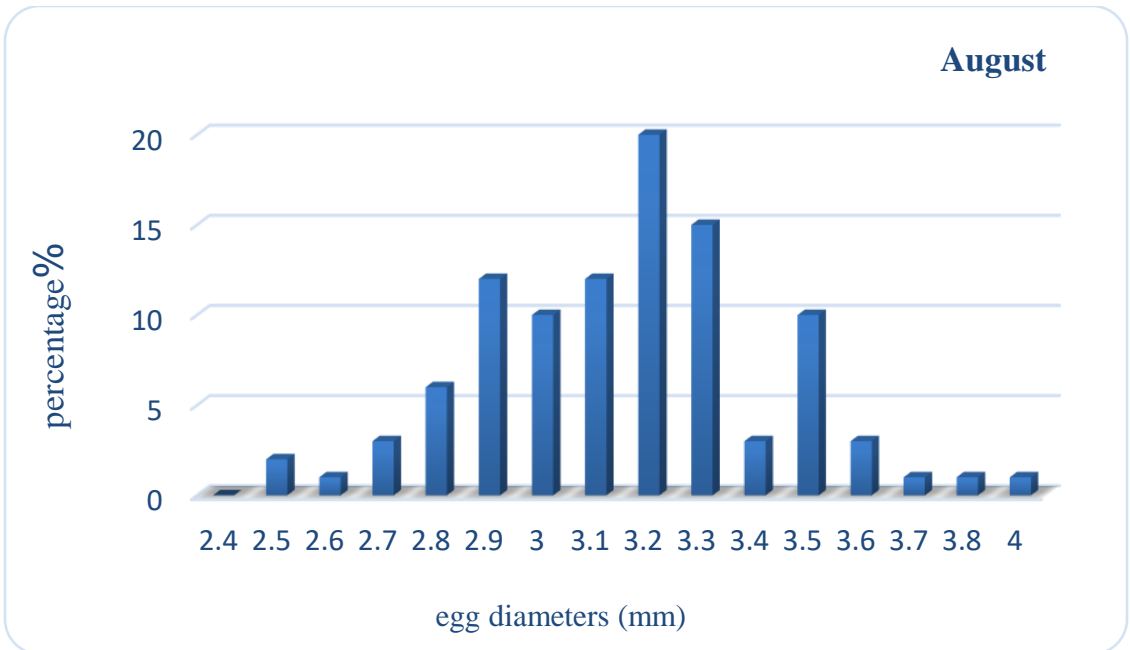

Figure 13 (c). Development of egg diameters and their percentages of females of the species Tristramella simonis during reproduction season (August).

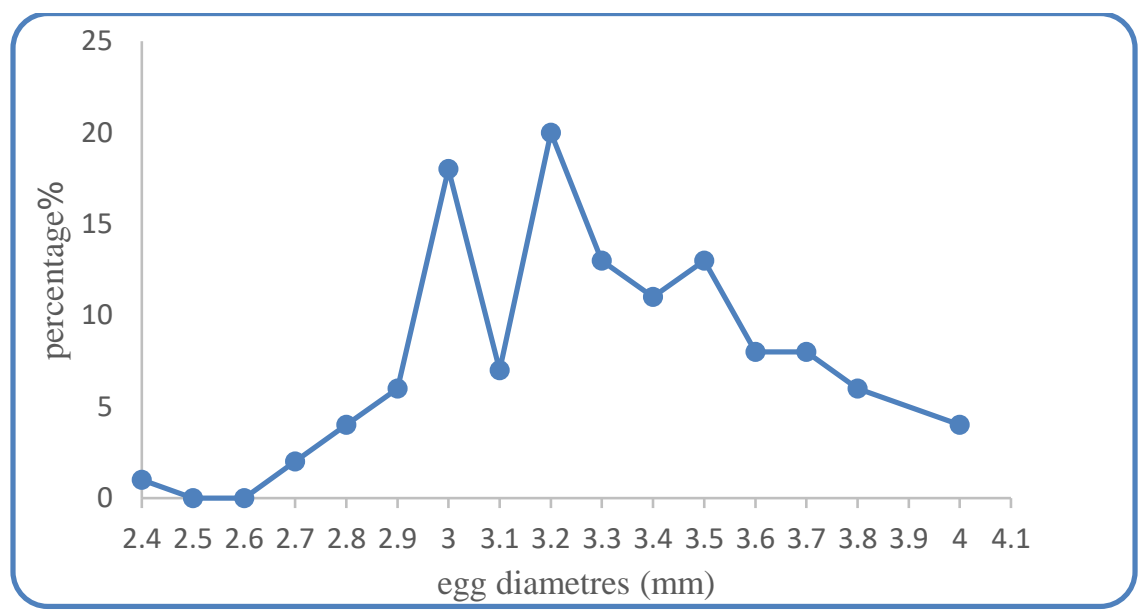

Figure 14. Cumulative frequency curve of egg diametes of females of the species Tristramella simonis. 


\section{CONCLUSION}

The reproduction period of T.simonis was between April and August with three obvious peaks of maturity.The lengthat first maturity (L50), is $13.31 \mathrm{~cm}$ for females and $14.87 \mathrm{~cm}$ for males. The absolute fecundity ranged from 940 to 1229 egg. While the relative fecundity ranged between 158- 215 egg/ g of ovary weight.

\section{ACKNOWLEDGMENTS}

We thank the fishermen, especially the fisherman Ali Hassan who helped us in the process of catching fish specimens.

\section{CONFLICT OF INTEREST STATEMENT}

We declare that we have no conflict of interest.

\section{AUTHOR'S CONTRIBUTION}

All authors contributed equally to this research work.

\section{REFERENCES}

Ali, A., A. Saad and L. Jawad. 2015. Confirmation of the Presence of the Indian Stinging Catfish, Heteropneustes Fossilis (Bloch, 1794) (Heteropneustidae) in Syrian inland waters. J. Appl. Ichthyol. 32: 117-119.

Ali, A., A. Tarif., D. Ballout., F. Deeb and A. Halloum. 2013. The effect of peat water on the biological diversity of fish fauna in the northern great River. Seminar "Developing Agricultural Production in the Syrian Coast (Problems and Solutions)". Lattakia, 15- 16 April. Tishreen University, Syria.

MOWR: Ministry of Water Resources 2010. Annual report of the Water Quality Monitoring Department. Water Resources Directorate, Lattakia, Syria. p. 194.

Bagenal, T. B. 1973. Fish fecundity and its relations with stock and recruitment. Rapports et Proces-verbaux Reunion Conseil international pour l'Exploration de la Mer. 164: 186-198.

Bagenal, T. B. 1978. Aspects of fish fecundity in ecology of freshwater fish production. Blackwell Scientific Publications. p. 75-102.

Beckman, W. C. 1962. The Freshwater Fishes of Syria and Their General Biology and Management. Fisheries Division, Biology Branch, Food and Agriculture Organization of the United Nations. p. 297.

Borkenhagen, K., J. Freyhof. 2009. New Records of the
Levantine Endemic Cichlid Tristramella Simonis from Syria. Cybium. 33: 335-336.

Bougis, P. 1952. Recherches biometriques surls rougetes (mullus barbatus et mullus sumuleus). Zool, exp. gen. 89: 57-174.

Coad, W. B. 2010. Freshwater Fishes Of Iraq. SofiaMoscow. p. 295.

El-Karachily, A. F., Z. M. EL-Khalek., S. A. Fattouh. 2001. Fish production \& Consumption in African \& Asian Arab Countries \& its Forecasting. http://www.ifremer.fr/avano/.

GORS: General Organization of Remote Sensing. Lattakia Governorate. 2017.

Gunderson, D. R. 1977. Population Biology of Pacific Ocean Perch, Sebastes Alutus, Stocks in the Washington-Queen Charlotte Sound Region, and Their Response to Fishing. Fish. Bull. 75: 369-403.

Khalifa, S. Z. 2017. Ecological and biological of Nile tilapia Oreochromis niloticus and blue tilapia Oreochromis aureus from Tigris River Southern Baghdad. Thesis submitted to Diyala University. p. $16-141$.

Kullander, S. O. 1998. A Phylogeny and Classification of the South American Cichlidae (Teleostei: Perciformes) in Malabarba. L. R.; Reis, R. E.; Vari, R. P.; Lucena, Z. M. S. \&Lucena, C. A. S. (eds), Phylogeny and Classification of Neotropical Fishes. Edipucrs ,Porto Alegre. p. 461-498.

Love, R. M. 1970. The chemical biology of fish. Acd. Pr. London. New York. p. 89-97.

Pravdin, G. V. 1966. Methods in Ichthyology. Moscow. High school. p. 256.

Saad, A., N. Hammoud., Gh. Khalaf., Gh. Alzin., E. Al Hawi and A. Ali. 2006. A comparative study of the biological diversity of fish fauna in the Orontes River basin in both Syria and Lebanon. Sustainable Agricultural Development and Food Security Conference, Tishreen University.

Sabour, W. 1995. A study of the biology of Sultan Ibrahim fishes (Mullidae) in the waters of the Syrian coast (Lattakia region). Master thesis, Faculty of Science, Tishreen University. p. 256.

Snoeks, J., and G. G. Teugels. 1991. Tristramella. (PP 519520). In J. Daget, J. Gosse, G. Teugels, D.F.E. Thys van den Audenaerde (eds.).Check-list of the Freshwater Fishes of Africa. Paris: ORSTOM. Vol. (4). 
Publisher's note: EScience Press remains neutral with regard to jurisdictional claims in published maps and institutional affiliations.

(C) (†)

Open Access This article is licensed under a Creative Commons Attribution 4.0 International License, which permits use, sharing, adaptation, distribution and reproduction in any medium or format, as long as you give appropriate credit to the original author(s) and the source, provide a link to the Creative Commons license and indicate if changes were made. The images or other third-party material in this article are included in the article's Creative Commons license, unless indicated otherwise in a credit line to the material. If material is not included in the article's Creative Commons license and your intended use is not permitted by statutory regulation or exceeds the permitted use, you will need to obtain permission directly from the copyright holder. To view a copy of this license, visit http://creativecommons.org/licenses/by/4.0/.

(C) The Author(s) 2020 . 